\title{
Video as an effective knowledge transfer tool to increase awareness among health workers and better manage dengue fever cases
}

\author{
Christian Dagenais $^{1}$ (D), Catherine Hébert $^{1}$ (D), Valéry Ridde ${ }^{2}$ (D) \\ 1 Psychology Department, University of Montreal, 2 École de Santé Publique, Social and Preventative Medicine Department, University of Montreal \\ Keywords: burkina faso, dengue, video, knowledge transfer \\ https://doi.org/10.29392/001c.29879
}

Journal of Global Health Reports

Vol. 5, 2021

\begin{abstract}
Background
For a patient with dengue fever, a wrong diagnosis can be fatal. Unfortunately, very few Burkinabé health workers are adequately trained to diagnose and treat cases of dengue fever. Recent outbreaks of dengue fever in Burkina Faso, which carries a significant malaria burden, have made updating health workers' knowledge urgent. Following a trial to determine the most appropriate format, a video was specially developed as a knowledge translation tool to update health workers' knowledge.
\end{abstract}

\begin{abstract}
Methods
The video was sent to front-line medical staff. Within four months, it was viewed by 2,993 people. A qualitative evaluation was conducted using the Theory of Planned Behaviour. Twenty-one health professionals who viewed the video agreed to participate in interviews on which content analysis was performed.
\end{abstract}

\section{Results}

The uptake of the knowledge in the video was mainly influenced by the fact that its format was adapted to the target audience, that it presented specific and concise information, that it conveyed a relevant message in everyday language, and that the participants urgently needed the content.

\section{Conclusions}

Video development as a knowledge transfer tool is an effective and efficient way to update health workers' knowledge and influence their practices. Users received the video enthusiastically due to the epidemic context.

A viral disease transmitted to humans by mosquitoes of the genus Aedes, the dengue virus, is rampant in tropical and subtropical regions. Over the past two decades, the average annual number of cases of dengue haemorrhagic fever has risen, ${ }^{1}$ with a sixfold increase in incidence from 1990 to $2013 .^{2}$ Dengue fever is now considered an epidemic in over 100 countries across America, Asia, Oceania, and Africa. ${ }^{3}$ In 2010, the World Health Organization (WHO) announced that the cases of hemorrhagic fever caused by dengue had increased spectacularly over the past few years. ${ }^{1}$

Burkina Faso is a West African nation that experienced a dengue epidemic in $2013^{4}$ and again in 2016.5,6 Studies conducted in Burkina Faso have found that healthcare providers lack knowledge of dengue and few received training on non-malaria febrile diseases. ${ }^{7,8}$ The virus is often confused with malaria, as the symptoms of the two diseases are similar, but taking antimalarial drugs can worsen the condition of a patient with dengue fever. Therefore, there is an urgent need to raise awareness and improve knowledge in Burkina Faso about the management of non-malaria febrile diseases. ${ }^{7}$
Despite concerted efforts over decades, a gap remains between the production of scientific evidence and its use, both in Africa and around the world. This gap is attributed to a lack of timely access to relevant research by healthcare providers and decision-makers that would help guide their work. ${ }^{9,10}$ Another contributing factor is a lack of training in reading and critiquing scientific research, along with most research not being accessible in its traditional format (i.e. scientific journals) to the majority of practitioners and decision-makers. ${ }^{11}$

A recent resurgence of dengue in Burkina Faso ${ }^{12}$ calls for the implementation of responses that are quick, effective, easily accessible, and based on the most up-to-date information available. ${ }^{13}$ Digital interventions offer a possible solution, ${ }^{14,15}$ which can contribute to health promotion, disease prevention, and health education. ${ }^{4,16}$ Referred to as eHealth technologies, Information Technology or Information and Communication Technologies (ICTs), ${ }^{14,15}$ these interventions have demonstrated their potential to extend and intensify the delivery of medical treatments to thousands of patients in developing nations. ${ }^{15}$ Their use is considered 
one of the most important methods of improving the quality of services in these countries. ${ }^{17,18}$

\section{METHODS}

The study presented in this article is a follow-up to an experiment that assessed video as a digital solution for transferring knowledge on dengue fever in Burkina Faso. ${ }^{13}$ The aim of that first study was to determine which narrative genre (journalistic, dramatisation, or computer graphics animation) was most effective in transmitting knowledge about dengue fever to health professionals. The goal was to influence their practice so that dengue fever cases could be better diagnosed and treated. This study identified which narrative elements (audio and visual) fostered knowledge transmission and retention. A video was produced, based on this evidence. This video was posted on a website in October 2017, and a link to the site was sent to all health workers in the country by the Ministry of Health. In four months, the video was viewed by 2,993 people, 910 of whom viewed it in its entirety. At the end of the video, participants were invited to answer a short survey and provide their contact details to participate in a qualitative interview. The objective was to learn what influence the video had on their practice. The tool developed by Boyko et al., 2011, based on the Theory of Planned Behaviour, inspired the development of the qualitative interview guide. Its goal was to understand the a) attitudes, b) subjective norms, and c) perceptions of control over the target behaviour. Twenty-one respondents were contacted; five were decision-makers, two were the heads of an NGOs, six were nurses, four were midwives, one a pharmacist and one a doctor. Twenty-one respondents were contacted, and interviews lasting 20 to 40 minutes were conducted by telephone and audio recorded. A single research professional, supervised by the principal investigator of the first study $(\mathrm{CH})$, led the interviews. These audio files were imported into the qualitative data processing software NVivo ${ }^{\circledR}$ and partially transcribed. The comments collected were analysed using a thematic analysis method that made it possible to identify, group, and structure all the themes addressed in the interviews. ${ }^{19}$ Each theme was summarised to understand better the different names given to things, the participants' reasoning, and the factors that influenced their perceptions. Next, the transcript analysis was submitted to a research professional and subjected to an interrater agreement.

\section{RESULTS}

Attitude. Participants' reception to the video was unanimously positive. They experienced a sense of satisfaction and even elation after viewing it. The video was appreciated for the education it provided. Not only did it meet a need for information, but it also standardised the front-line medical approach. The video transmitted specific and concise information that increased their knowledge and understanding of dengue fever:

"I can say the video is short and specific. The key points are made briefly so it can be viewed without losing too much time and without becoming impatient and aban-
| doning it." (Midwife)

The positive assessment of the video was also based on the relevance of the message, which was considered essential given the dengue fever outbreaks. Participants greatly appreciated that the video was in French and clarified the terminology in current use. A midwife stated that the video led her to adopt appropriate terminology and to correct colleagues who are misusing it:

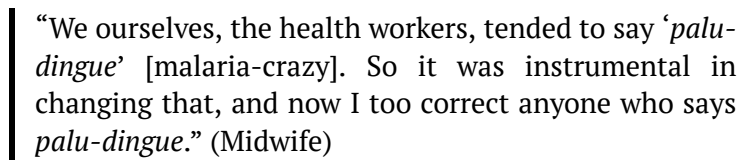

Respondents' attitudes were also strongly influenced by the epidemic context. Health workers have been worried since the 2013 dengue epidemic. The video could serve as a tool for raising awareness or alerting the medical community. Some reported having witnessed fatal cases of dengue fever, which made the epidemic more palpable and the desire to fight it more personal. A nurse highlighted the usefulness of the video at a time when the illness is progressing.
"The video was welcome. I received the video when dengue fever was at a very high level at the CMA [satel- lite medical centre] in Nouna. There were cases every day." (Nurse)

The lessons learned, the summary format, the relevance of the message, and the epidemic context thus appeared to make respondents receptive to integrating the video's content into their practice.

Subjective norms. Subjective norms suggest that the social environment can influence the individual's behaviour and intention to act. For example, respondents expressed a strong sense of belonging to the health professional community by systematically sharing the video through social networks, thus encouraging others to integrate this knowledge. This was the case of a pharmacist who felt the need to share the video with his colleagues.
"Dengue fever is a disease of global concern. It was im- portant for everyone to learn what this disease is, and if there are ways [to cope with it], everyone should adopt them for protection. It was with this in mind that I re- ceived the link and wanted to share it with my col- leagues so everyone could become aware." (Pharmacist)

The respondents did not view the reactions of their colleagues and superiors as hindering the use of the knowledge because they were confident those reactions would be positive.

Perception of control over one's behaviour. Health workers' perceptions of how much control they had over their behaviour influenced their intention to act. Respondents working in clinics all emphasised the healthcare provider's autonomy. In their view, there was no restriction on applying scientific data, as long as the data were considered credible, which was the case with this video.

"The staff member is quite autonomous; he does not
need third-party authorisation to be able to diagnose,
because he is the one in charge, so there is nothing to 
| worry about.” (District Medical Officer)

It should be noted that half the respondents indicated that the information in the video was in line with Ministry of Health guidelines, which reinforced its integration into their practice. However, only three of those respondents treated patients directly. As the rest were in management positions, it is to be expected that they would be more aware of national guidelines. The other half of respondents deplored the lack of information on dengue fever and its treatment. The video was likely to change practices:

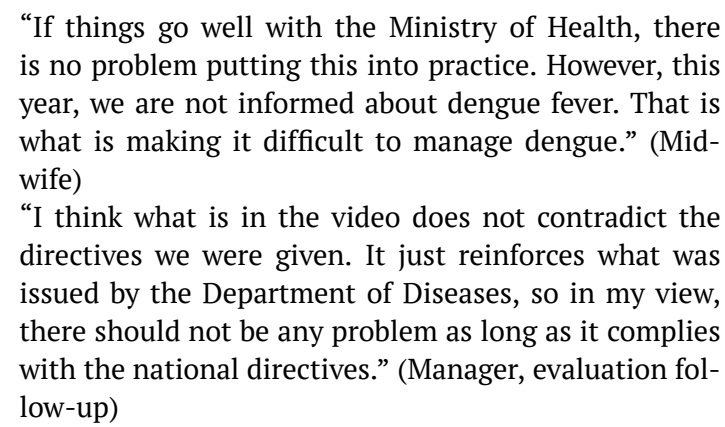

The healthcare providers thus had the autonomy required to integrate new knowledge into their practice and affirmed that they had complete control over what they did in consultations.

\section{DISCUSSION}

Given the epidemic context, users welcomed the video enthusiastically. As recommended, ${ }^{20}$ the video was developed based on evidence to serve the training needs of health professionals in Burkina Faso. It aimed to influence their practice and increase the number of cases correctly diagnosed as dengue fever.

Their positive attitude towards the video fostered respondents' intention to use the knowledge it presented. This attitude was mainly influenced by the video relaying specific and concise information, transmitting a relevant message in everyday language, and responding to the crisis context. Subjective norms did not appear to play a significant role in the intention to use knowledge. Their perception of control over their behaviour was affected by the national dengue fever management guidelines. However, these guidelines were unknown to half the respondents.

A careful analysis of intervention studies shows that simply disseminating written guidelines is relatively ineffective in increasing the performance of health workers compared to digital solutions. ${ }^{21}$ Therefore, digital solutions offer an increasingly popular alternative for training health workers in Africa. ${ }^{15,16}$ Among the many benefits of digital interventions are 1) increased access to health care and health information, 2) greater efficacy and a lower cost of service delivery, 3) timely access to information, and 4) expanding access to continuing medical education and training for health workers. ${ }^{22}$

The current study demonstrates that the use of video as a digital intervention met the expectations and training needs of the health workers surveyed. Future research should explore the impact of technology when more broadly used and disseminated, ${ }^{13}$ for example, using mobile devices (e.g. cell phones, tablets). These simple, accessible, and ubiquitous devices are already part of the daily life of health workers and community service providers in low- and medium-income countries, ${ }^{13,23-27}$ and may support various health practices such as data collection, service delivery, and patient adherence to recommendations. ${ }^{16,24}$ These technologies should be developed rapidly ${ }^{16}$ and their use supported in Africa.

\section{CONCLUSIONS}

Using video as a knowledge transfer tool is an effective and efficient way to update health workers' knowledge and influence their practices. Respondents received the video enthusiastically because of the epidemic context, which required fast, effective, and evidence-based actions. Therefore, it is essential to test video as a tool to transfer knowledge and change health workers practices in the context of other health crises

\section{ACKNOWLEDGEMENTS}

The authors would like to thank Ahmed Sie Barro and the participants who agreed to answer our questions.

\section{ETHICS APPROVAL AND CONSENT TO PARTICIPATE}

This study was approved by the health research ethics committees of the Government of Burkina Faso (decision no. 2015/10/06) and of the University of Montreal Hospital Research Centre (decision no. 15-190). Participants' consent was obtained orally.

\section{FUNDING}

VR. ROH-115213; Community research studies and interventions for health equity in Burkina Faso

VR. DC0190GP; Planning and Dissemination Grant- Institute Community Support

Supported by the Canadian Institute of Health Research.

\section{AUTHORSHIP CONTRIBUTIONS}

CD conducted the research and investigation processes. He prepared and wrote the manuscript.

$\mathrm{CH}$ contributed to the collection and analysis of data and the revision of the different versions of the manuscript.

VR participated in the formulation of the project and the revision of the different versions of the manuscript. He participated in obtaining financial support for the project.

\section{COMPETING INTERESTS}

The authors completed the Unified Competing Interest form at http://www.icmje.org/disclosure-of-interest/ (available upon request from the corresponding author) and declare no conflicts of interest. 


\section{CORRESPONDENCE TO:}

Professor Christian Dagenais, Ph.D.

Full Professor, Psychology Department University of Montreal

Pavillon Marie-Victorin, Bureau C-355

Montréal, Québec, H3C 3J7

CANADA
Principal Investigator, Équipe RENARD

www.equiperenard.ca

Submitted: March 08, 2021 GMT, Accepted: October 07, 2021 GMT 


\section{REFERENCES}

1. Guzman MG, Halstead SB, Artsob H, et al. Dengue: A continuing global threat. Nat Rev Microbiol. 2010;8(S12):S7-S16. doi:10.1038/nrmicro2460

2. Stanaway JD, Shepard DS, Undurraga EA, et al. The global burden of dengue: an analysis from the Global Burden of Disease Study 2013. Lancet infect dis. 2016;16(6):712-723. doi:10.1016/s1473-3099(16)0002 6-8

3. Rodenhuis-Zybert IA, Wilschut J, Smit JM. Dengue virus life cycle: Viral and host factors modulating infectivity. Cell Mol Life Sci. 2010;67(16):2773-2786. d oi:10.1007/s00018-010-0357-z

4. Tarnagda Z, Congo M, Sagna T, et al. Outbreak of dengue fever in Ouagadougou, Burkina Faso, 2013. Int J Microbiol Immunol Res. 2014;2(7):101-108.

5. Baronti C, Piorkowski G, Touret F, Charrel R, de Lamballerie X, Nougairede A. Complete coding sequences of two dengue virus type 2 strains isolated from an outbreak in Burkina Faso in 2016. Genome Announc. 2017;5(17):e00209-00217. doi:10.1128/geno mea.00209-17

6. World Health Organisation (WHO). Emergencies preparedness, response. Dengue Fever-Burkina Faso. Published 2016. http://www.who.int/csr/don/18-nove mber-2016-dengue-burkina-faso/en/

7. Bottger C, Bernard L, Briand V, Bougouma C, Triendebeogo J, Ridde V. Primary healthcare providers' practices related to non-malarial acute febrile illness in Burkina Faso. Trans $R$ Soc Trop Med Hyg. 2017;111(12):555-563. doi:10.1093/trstmh/try00 $\underline{9}$

8. Munoz M, Ridde V, Yaro S, Bottger C. Beyond Ebola: Surveillance for all hemorrhagic fever in West Africa should be enhanced. Pan Afr Med J. 2015;(Suppl1):22. doi:10.11694/pamj.supp.2015.2 2.1.5837

9. Dagenais C, Somé TD, Boileau-Falardeau M, McSween-Cadieux E, Ridde V. Collaborative development and implementation of a knowledge brokering program to promote research use in Burkina Faso, West Africa. Global Health Action. 2015;8(1):26004. doi:10.3402/gha.v8.26004

10. Dagenais C, McSween-Cadieux E, Somé PA, Ridde V. A knowledge brokering program in Burkina Faso (West Africa); reflections from our experience. Health Syst Reform. 2016;2(4):367-372. doi:10.1080/2328860 4.2016.1202368
11. Dagenais C, Queuille L, Ridde V. Evaluation of a knowledge transfer strategy from a user fee exemption program for vulnerable populations in Burkina Faso. Glob Health Promot. 2013;20(Supp. 1):70-79. doi:10.1177/1757975912462416

12. Ouédraogo S, Degroote S, Barro SA, Somé PA, Bonnet E, Ridde V. Épidémies récurrentes de la dengue au Burkina Faso : Préférences communautaires pour une intervention de prévention de la maladie. Rev Épidémiol Santé Publique. 2018;67(2019):375-382. doi:10.1016/i.respe.2019.08.0 $\underline{02}$

13. Hébert C, Dagenais C, Mc Sween-Cadieux E, Ridde $\mathrm{V}$. Video as a public health knowledge transfer tool in Burkina Faso: A mixed evaluation comparing three narrative genres. PLoS Negl Trop Dis. 2020;14(6):e0008305. doi:10.1371/journal.pntd.00083 $\underline{05}$

14. Black AD, Car J, Pagliari C, et al. The Impact of eHealth on the Quality and Safety of Health Care: A Systematic Overview. Djulbegovic B, ed. PLoS Med. 2011;8(1):e1000387. doi:10.1371/journal.pmed.10003 $\underline{87}$

15. Blaya JA, Hamish SFF, Holt B. E-Health Technologies Show Promise in Developing Countries. Health Aff. 2010;29(2):244-251. doi:10.1377/hlthaff.2 $\underline{009.0894}$

16. Aranda-Jan CB, Mohutsiwa-Dibe N, Loukanova S. Systematic review on what works, what does not work and why of implementation of mobile health (mHealth) projects in Africa. BMC Public Health. 2014;14:188. doi:10.1186/1471-2458-14-188

17. Mastellos N, Tran T, Dharmayat K, et al. Training community healthcare workers on the use of information and communication technologies: A randomised controlled trial of traditional versus blended learning in Malawi, Africa. BMC Med Educ. 2018;18(1). doi:10.1186/s12909-018-1175-5

18. World Health Organization (WHO). Resolution WHA58.28 EHealth. 58th World Health Assembly. Geneva; 2005.

19. Paillé P, Mucchielli A. L'analyse Qualitative En Sciences Humaines et Sociales. 3rd ed. Armand Colin; 2012. doi:10.3917/arco.paill.2012.01 
20. Innis J, Dryden-Palmer K, Perreira T, Berta W. How do health care organizations take on best practices? A scoping literature review. Int J Evid Based Healthc. 2015;13(4):254-272. doi:10.1097/xeb.000000 0000000049

21. Rowe AK, de Savigny D, Lanata CF, Victora CG. How can we achieve and maintain high-quality performance of health workers in low-resource settings? Lancet. 2005;366(9490):1026-1035. doi:10.1 $\underline{016 / \mathrm{s} 0140-6736(05) 67028-6}$

22. Mechael P, Batavia H, Kaonga N, Searle S, A K, et al. Barriers and Gaps Affecting MHealth in Low and Middle Income Countries: Policy Whyte Paper. The Earth Institute Columbia University; Mhealth Alliance; 2010.

23. Benoit M, Queille L, Ridde V. Que sait-on de l'utilisation du téléphone portable pour les interventions de santé (mHealth) en Afrique? Projet Grands Défis Canada. Published online August 2013.
24. World Health Organization (WHO). MHealth: New Horizons for Health through Mobile Technologies: Second Global Survey on EHealth. World Health Organization; 2011.

25. Danis CM, Ellis JB, Kellogg WA, et al. Mobile phones for health education in the developing world: SMS as a user interface. Proceedings of the First ACM Symposium on Computing for Development. Published online 2010:1-9. doi:10.1145/1926180.1926197

26. Diese M, Kalonji A, Izale B, et al. Communitybased maternal, newborn, and child health surveillance: Perceptions and attitudes of local stakeholders towards using mobile phone by village health volunteers in the Kenge Health Zone, Democratic Republic of Congo. Published online 2018. doi:10.6084/m9.figshare.c. 4023055

27. Greenleaf AR, Ahmed S, Moreau C, Guiella G, Choi Y. Cell phone ownership and modern contraceptive use in Burkina Faso: Implications for research and interventions using mobile technology. Contraception. 2019;99(3):170-174. doi:10.1016/j.contraception.201 $\underline{8.11 .006}$ 